\title{
Examining the needs of affordable upper limb prosthetic users in India: A questionnaire-based survey
}

\author{
Vikranth Harthikote Nagaraja ${ }^{\mathrm{a}}$, Jeroen Henricus Maria Bergmann ${ }^{\mathrm{a}}$, Dibakar Sen ${ }^{\mathrm{b}}$ and \\ Mark Stuart Thompson ${ }^{\mathrm{a}, *}$ \\ ${ }^{a}$ Institute of Biomedical Engineering, University of Oxford, UK \\ ${ }^{\mathrm{b}}$ Centre for Product Design and Manufacturing, Indian Institute of Science, Bangalore, India
}

\begin{abstract}
.
BACKGROUND: In 2013 alone, 5000 new cases of Upper limb (UL) loss in India were reported. This segment has been poorly understood, with limited or no access to quality prosthetic rehabilitative care. Furthermore, very few studies have been carried out to capture their needs and concerns.

OBJECTIVE: To understand demographics and needs of UL prosthesis users belonging to low- and middle-income settings in India. Additionally, this study focuses at gaining insights on patient satisfaction levels, patterns of wear, challenges faced, patient priorities, and affordability.

METHODS: The questionnaire-based survey data $(\mathrm{n}=60)$ were acquired through telephone for 53 patients and direct interview for 7 patients and the replies were subjected to statistical analysis.

RESULTS: The study reveals that currently available prosthetic arms are not enabling the users to achieve desired functional and satisfaction levels. For a prosthetic UL to be affordable in this context, a price less than Indian Rupee (INR) 20,000 with an instalment mode of payment is preferred.

CONCLUSIONS: Major design priorities of the patients are functionality, comfort, and durability. Further, providing a subsidy, minimising delays in limb provision and fitting could maximise long-term prosthetic use and enable a much greater rate of acceptance.
\end{abstract}

Keywords: Upper limb prosthesis, affordability, questionnaire-based survey, wear patterns, design priorities, satisfaction levels

\section{Background}

Designs of upper limb (UL) prostheses ranging in cosmesis and functionality have evolved rapidly to address a variety of user needs and lifestyles with a final goal of restoring levels of functionality and quality of life (QoL) [1-3]. Although consensus on quantitative outcome measures for UL prostheses is lacking, reports from developed world users focus on

* Corresponding author: Mark S. Thompson, Institute of Biomedical Engineering, Department of Engineering Science, Parks Road, University of Oxford, Oxford OX1 3PJ, UK. Tel.: +44 1865737845 ; E-mail: mark.thompson@eng.ox.ac.uk. device acceptance, patterns of wear, common complaints, and satisfaction levels across various prosthesis types [4-8]. Some reports also elicited users' design and research priorities for future development $[9,10]$. Several publications have documented available prosthetics and assistive devices and their provision in lowincome countries [11-16].

However, only a few have surveyed the users of these devices in developing countries $[17,18]$, and studies of prosthesis users specifically in India are more limited. Kumar et al. [19] suggested increasing prosthetic acceptance by focusing on functionality levels regained by users and identifying reasons for noncompliance. Previous work identified the demograph- 


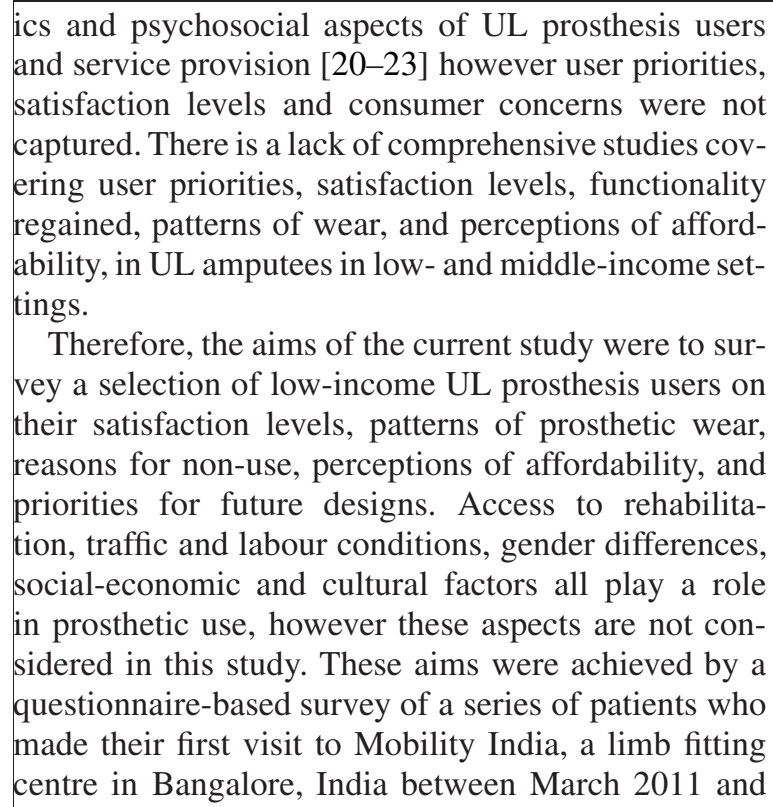
regained, patterns of wear, and perceptions of affordability, in UL amputees in low- and middle-income settings.

Therefore, the aims of the current study were to survey a selection of low-income UL prosthesis users on their satisfaction levels, patterns of prosthetic wear, reasons for non-use, perceptions of affordability, and priorities for future designs. Access to rehabilitation, traffic and labour conditions, gender differences, social-economic and cultural factors all play a role in prosthetic use, however these aspects are not considered in this study. These aims were achieved by a questionnaire-based survey of a series of patients who made their first visit to Mobility India, a limb fitting centre in Bangalore, India between March 2011 and March 2013.

\section{Methods \\ 2.1. Ethical approval \\ Ethical approval for this study was obtained from the Institute Human Ethics Committee, Indian Institute of Science, Bangalore. \\ 2.2. The questionnaire}

A detailed questionnaire was developed by adapting validated UL prosthesis questionnaires $[4,8,19,24]$. Due to a lack of consensus in this field, recommendations from Upper Limb Prosthetic Outcome Measures (ULPOM) Group [25] were incorporated in the questionnaire by setting it within the framework of World Health Organization-International Classification of Functioning, Disability and Health (WHO-ICF) model [26]. Data were sought on demographics, prosthesis history, patterns of wear, functional needs, satisfaction, design priorities, and affordability of a prosthesis. The questions were sequenced to elicit first general and then specific feedback and any potentially sensitive questions were asked at the end. The questionnaire is summarized in Table 1 . The section on affordability began by asking whether patients had received the official governmental subsidy in order to afford a prosthetic arm. This subsidy is provided to patients below the National Poverty Line which is set at per capita consumption expenditure per month of Indian Rupee (INR) 1,000 or less [27]

\subsection{Target population and sampling strategies}

Patient recruitment was through the NGO, Mobility India, which runs a limb fitting centre in Bangalore, India for patients predominantly from lowincome groups. All 82 new patients accepted for treatment at this centre between March 2011 and March 2013 were considered for inclusion. The contact details of the patients or the parents/guardians of the patients (who were under 18 years of age) were obtained from the rehabilitation team at the NGO centre. The authors contacted the patients by telephone to ask if they were interested to participate in the study. Inclusion criteria were: UL loss or absence at any level; experience of at least 3 months of prosthetic use. Exclusion criteria were: bilateral affect; neither Hindi nor Kannada spoken. These considerations excluded 15 patients and a further 7 were uncontactable due to unavailability of latest telephone numbers; so 60 unilateral UL amputees were surveyed using the questionnaire.

\subsection{Data collection}

Telephone interviews $(\mathrm{n}=53)$ and face-to-face interviews $(\mathrm{n}=7)$ were performed by a single interviewer (VHN) in the interviewee's preferred language (Hindi or Kannada). Most people who were interviewed by phone either lived in regions generally far away from Bangalore and/or did not have an appointment scheduled at the limb fitting centre during the study period. Face-to-face interviews were held at the NGO limb fitting centre (Mobility India, Bangalore) with patients who happened to have their appointment(s) scheduled during the study period. Feedback from children under the age of 12 was obtained through their parents or guardians. All data were anonymised before storage.

\subsection{Data analysis}

Quantitative data were analysed using Matlab $2010 a^{\circledR}$ and Microsoft Excel $2010^{\circledR}$ software. Frequency counts and three measures of central tendency (Mean, Median, and Mode) were used where appropriate. Design priorities were compared across three groups (Cosmetic, Body-powered, and Myoelectric) using the non-parametric Friedman test: a priority score $\left(P_{d}\right)$ was calculated for the $d^{\text {th }}$ design consideration according to Eq. (1) [10]:

$$
P d=\sum_{r=1}^{6} \frac{(6-r) \cdot f d(r)}{6 N}
$$


VH. Nagaraja et al. / Examining the needs of affordable upper limb prosthetic users in India: A questionnaire-hased survey

\begin{tabular}{|c|c|c|c|}
\hline \multicolumn{4}{|c|}{$\begin{array}{c}\text { Table } 1 \\
\text { Breakdown of questionnaire content }\end{array}$} \\
\hline Section & Topic & No. and type of questions & Relevant factors \\
\hline \multirow[t]{9}{*}{$\mathrm{I}$} & Patient demographics & 1 - Categorical & Age \\
\hline & & 4 - Dichotomous & Gender \\
\hline & & 3 - Numerical & Qualification level \\
\hline & & 1 - Ordinal & Side of amputation \\
\hline & & & Dominant before amputation \\
\hline & & & Level of amputation \\
\hline & & & Number of years since amputation \\
\hline & & & What was your amputation a result of? \\
\hline & & & Number of years since prosthetic limb was fitted \\
\hline \multirow[t]{2}{*}{ II } & Occupation status & 2 - Open-ended & Before amputation \\
\hline & & & After prosthesis fitting \\
\hline \multirow[t]{4}{*}{ III } & Prosthesis use and satisfaction & 3 - Ordinal & Functional usage duration of prosthesis/day \\
\hline & & $10-$ Likert & Daily wear \\
\hline & & & Function level \\
\hline & & & $\begin{array}{l}\text { Colour, Shape, Noise, Appearance, Weight, Usefulness, Re- } \\
\text { liability, Fit, Comfort, Overall satisfaction }\end{array}$ \\
\hline \multirow[t]{3}{*}{ IV } & $\begin{array}{l}\text { Prosthesis use and personal views } \\
\text { on prosthesis }\end{array}$ & 2 - Categorical & Past prosthesis \\
\hline & & 1 - Ordinal & Current prosthesis \\
\hline & & & Prosthesis design priorities \\
\hline \multirow[t]{4}{*}{$\mathrm{V}$} & $\begin{array}{l}\text { Reduced use/Non-wear of pros- } \\
\text { thesis and dissatisfaction }\end{array}$ & 2 - Open-ended & Common complaints \\
\hline & & 1 - Multiple choice & Challenges encountered in daily life \\
\hline & & 1 - Ordinal & Reasons for non-wear/reduced wear duration \\
\hline & & & Overall delay in prosthetic limb delivery \\
\hline \multirow[t]{2}{*}{ VI } & Qualitative experiences & 2 - Open-ended & Social and cultural requirements \\
\hline & & & $\begin{array}{l}\text { Additional comments/Feedback/Suggestions for future } \\
\text { prosthesis development }\end{array}$ \\
\hline \multirow[t]{8}{*}{ VII } & Affordability & 3 - Categorical & How did you get to know about this limb fitting centre? \\
\hline & & 3 - Ordinal & Proximity to this limb fitting centre \\
\hline & & 2 - Numerical & Travel time \\
\hline & & & Monthly income \\
\hline & & & Occupation type \\
\hline & & & Willingness to spend on a prosthesis \\
\hline & & & Financing options \\
\hline & & & Willingness to spend on repair/consumables \\
\hline \multirow[t]{2}{*}{ VIII } & $\begin{array}{l}\text { mHealth/Willingness to partici- } \\
\text { pate in future studies }\end{array}$ & 3 - Dichotomous & Do you own a mobile phone? \\
\hline & & & $\begin{array}{l}\text { Perceived need for mHealth initiative } \\
\text { Are you interested in participating in a future study in this } \\
\text { project? }\end{array}$ \\
\hline
\end{tabular}

where $N$ represents the number of patients in the group of interest, $f_{d}{ }^{\circledR}$ is the frequency with which the $d^{\text {th }}$ design concern was given a ranking, $r \in\{1,2, \ldots$. 6 w with $r=1$ denoting the highest design priority. A high value of $P_{d}$ reflects a design concern that is frequently considered a high priority. The reported values of $P_{d}$ have been normalized by the highest $P_{d}$ in each group. Rejection of prosthesis is defined as either a discontinuation of prosthesis usage or change in initially prescribed prosthesis/prosthesis type [10].

The Likert scale for satisfaction levels was quantified by assigning the levels Very dissatisfied, Dissatisfied, Neither satisfied nor dissatisfied, Satisfied, and Very satisfied a weighting of $-2,-1,0,+1$, and +2 respectively, enabling the calculation of a weighted av- erage. The Prosthesis Success Score (Table 2) was also calculated using the published method [8].

\section{Results}

\subsection{Sample population demographics}

Demographic data are presented as mean SD. Among the interviewed group $(n=60)$, the age of the paediatric group $(\mathrm{n}=6)$ was 6 SD 0.8 years with a range of 5-7 years, while that of the adult male population $(\mathrm{n}=51)$ was 31 SD 10.1 years with a range of $15-54$ years and adult female population $(\mathrm{n}=3)$ was 21 SD 5.3 years with a range of $15-28$ years. Male to 
4 V.H. Nagaraja et al. / Examining the needs of affordable upper limb prosthetic users in India: A questionnaire-based survey

Prosthetic success score

\begin{tabular}{lll}
\hline Prosthetic success score & & \\
\hline Functional usage duration of prosthesis/day & $6-8$ hours & 3 \\
& $4-6$ hours & 2 \\
& $2-4$ hours & 1 \\
& $<2$ hours & 0 \\
Daily wear/usage & $8-16$ hours & 3 \\
& $4-8$ hours & 2 \\
& $0-4$ hours & 1 \\
Function level & Rarely/Never wear & 0 \\
& Complex tasks & 3 \\
& Grasping/holding/lifting & 2 \\
Score rating in prosthetic rehabilitation/use & Supporting/balance/regular cosmetic use & 1 \\
& None/irregular cosmetic use & 0 \\
& $7-9$ & Good \\
& $5-7$ & Satisfactory \\
& $3-5$ & Fair \\
\hline
\end{tabular}

female ratio in the surveyed population was 9:1.100\%

of the patients were right-handed prior to amputation,

31 patients had lost their dominant arm, and 45 patients had a below elbow level of limb absence.

Fifty one patients (85\%) had had an amputation following trauma (either occupational or road traffic accidents) and the remaining 9 were atraumatic ( 8 cases of congenital amputations and 1 case of dysvascularity). Time since amputation to prosthesis fitting was $6 \mathrm{SD}$ 4.9 years. As expected, the occurrence of congenital limb absence was higher in the paediatric (100\%) than in the adult population (4\%), and involved predominantly below elbow limb absence. Prosthesis users in this survey had widely varying educational backgrounds with $12 \%$ having a degree, $68 \%$ educated to secondary level, $13 \%$ educated to primary level and $7 \%$ did not have any education. All patients had used their prosthesis for at least 3 months, with usage duration of 13 SD 8.5 months.

\subsection{Prosthesis history and usage}

Body-powered arms and cosmetic arms accounted for $93 \%$ of the prostheses used. All 60 patients preferred a hand-shaped terminal device (TD) over a hook-shaped TD. Rejection rates were low - only one patient had rejected the initially prescribed prosthesis. In this case the supplied cosmetic arm was upgraded to a body-powered arm for the sake of higher functionality.

Out of the whole population, $12 \%$ had lost their jobs and were no longer employed, $48 \%$ failed to regain their previous levels of employment. The $22 \%$ who did regain previous levels of employment had sedentary jobs that did not demand high functionality from their prosthesis. The remaining $18 \%$ were students both before amputation and after prosthesis fitting.

\subsection{Functional levels achieved through prosthesis}

Almost $90 \%$ of the patients (Fig. 1) used their prosthesis functionally for less than 6 hours/day and 50\% for less than 8-16 hours. The main reasons cited for not wearing their prosthesis were that the device was heavy, and the harness and socket were uncomfortable. $56 \%$ used their prosthesis regularly for cosmetic purposes or supporting the sound limb in bimanual tasks, while $30 \%$ of the patients used their prosthesis irregularly for cosmetic purposes. The Prosthetic Success Score (Table 3) summarises these results: only $7 \%$ of the patients achieved successful prosthetic rehabilitation (Good category). Two categories - (i) patients using body-powered arms, and (ii) patients with below elbow limb absence, showed higher scores.

\subsection{Design priorities for prosthesis}

Patients ranked the importance of design characteristics - function, durability, appearance, comfort, usability, and cost (Table 4). The rank of each feature was normalized against the design feature with the highest priority. Surprisingly users of cosmetic arms placed more importance on cost and comfort than appearance and durability while body-powered arm users valued function the most followed by cost and comfort. Users of myoelectric arms valued function and comfort most, followed by durability and usability. Overall, function was deemed most important followed by cost and comfort. The relative rankings of all the design priorities are illustrated in Table 4. 
VH. Nagaraja et al. / Examining the needs of affordable upper limb prosthetic users in India: A questionnaire-hased survey

Table 3

\begin{tabular}{|c|c|c|c|c|c|}
\hline \multicolumn{6}{|c|}{$\begin{array}{c}\text { Table } 3 \\
\text { Success achieved through prosthesis }\end{array}$} \\
\hline & $\begin{array}{l}\text { Cosmetic arm } \\
\mathrm{n}(\%)\end{array}$ & $\begin{array}{l}\text { Body-powered arm } \\
\mathrm{n}(\%)\end{array}$ & $\begin{array}{l}\text { Myoelectric arm } \\
\mathrm{n}(\%)\end{array}$ & $\begin{array}{l}\text { Above elbow level } \\
\mathrm{n}(\%)\end{array}$ & $\begin{array}{l}\text { Below elbow level } \\
\mathrm{n}(\%)\end{array}$ \\
\hline Good (7-9) & $0(0)$ & $3(10)$ & $0(0)$ & $0(0)$ & $3(7)$ \\
\hline Satisfactory (5-7) & $5(20)$ & $11(37)$ & $2(50)$ & $3(20)$ & $15(33)$ \\
\hline Fair $(3-5)$ & $10(38)$ & $10(33)$ & $0(0)$ & $5(33)$ & $15(33)$ \\
\hline Poor $(<3)$ & $11(42)$ & $6(20)$ & $2(50)$ & $7(47)$ & $12(27)$ \\
\hline Total - n (\%) & $26(100)$ & $30(100)$ & $4(100)$ & $15(100)$ & $45(100)$ \\
\hline Mean SD score & 4 SD 1.8 & $5 \mathrm{SD} 2.3$ & $4 \mathrm{SD} 2.8$ & $3 \mathrm{SD} 2.3$ & $5 \mathrm{SD} 2.0$ \\
\hline Range & $0-7$ & $0-9$ & $1-7$ & $0-7$ & $0-9$ \\
\hline
\end{tabular}

Table 4

Design priorities of prosthesis users (With relative rankings of importance given in parentheses for each column)

\begin{tabular}{|c|c|c|c|c|}
\hline Importance & Cosmetic arm $(n=26)$ & Body-powered $\operatorname{arm}(n=30)$ & Myoelectric $\operatorname{arm}(n=4)$ & Total $(n=60)$ \\
\hline 1 & $\begin{array}{l}\text { Cost (1.00) } \\
\text { Comfort (1.00) }\end{array}$ & Function (1.00) & Function (1.00) & Function (1.00) \\
\hline 2 & - & Cost $(0.71)$ & Comfort $(0.68)$ & Cost $(0.88)$ \\
\hline 3 & Appearance $(0.95)$ & Comfort $(0.61)$ & $\begin{array}{l}\text { Durability (0.64) } \\
\text { Usability }(0.64)\end{array}$ & Comfort $(0.84)$ \\
\hline 4 & Function (0.73) & Durability (0.56) & - & Appearance $(0.71)$ \\
\hline 5 & Durability $(0.71)$ & Usability (0.50) & Appearance $(0.50)$ & Durability (0.69) \\
\hline 6 & Usability (0.44) & Appearance $(0.44)$ & Cost (0.36) & Usability (0.54) \\
\hline
\end{tabular}



Fig. 1. Functional levels achieved though prosthesis.

\subsection{Satisfaction levels with current prosthesis}

Satisfaction levels for prosthesis attributes were measured on a Likert scale (Fig. 2). For cosmetic arms, satisfaction levels were lowest for colour and appearance with high dissatisfaction for weight and comfort. Body-powered arms showed the highest overall satisfaction levels.
Myoelectric arms showed poor satisfaction levels including noise. Weight and comfort were the major areas of dissatisfaction for all prostheses, while appearance and colour showed the lowest overall levels of satisfaction. $35 \%$ of the patients received their prosthesis within 4-6 weeks of their initial appointment, 5\% waited for $7-9$ weeks and the remaining $60 \%$ waited for a much longer duration ( $>9$ weeks). 
6 VH. Nagaraja et al. / Examining the needs of affordable upper limb prosthetic users in India: A questionnaire-based survey

Table 5

Common complaints faced by the patients

\begin{tabular}{|c|c|}
\hline Design aspects & Common complaints \\
\hline Appearance & Lack of adequate cosmesis, How others view my prosthesis? \\
\hline Comfort & $\begin{array}{l}\text { Donning/Doffing, Harness/Socket discomfort, Heat, Heavy, perspiration, Skin irritation, } \\
\text { Physical exertion, Overall discomfort }\end{array}$ \\
\hline Function & $\begin{array}{l}\text { Difficult to grasp and hold an object, Grasp of awkward shapes, Grasping of big/small } \\
\text { objects, Slipping of objects, Slow }\end{array}$ \\
\hline Control & Controlling is difficult, Long time to get adjusted to the device \\
\hline Maintenance & $\begin{array}{l}\text { Battery issues, Spring/cable getting cut, Glove staining/tearing, Harness breakage, Device } \\
\text { not being cleanable and/or not reliable }\end{array}$ \\
\hline Cost & Costly, Limb fitting centre is too far for any repair work \\
\hline
\end{tabular}

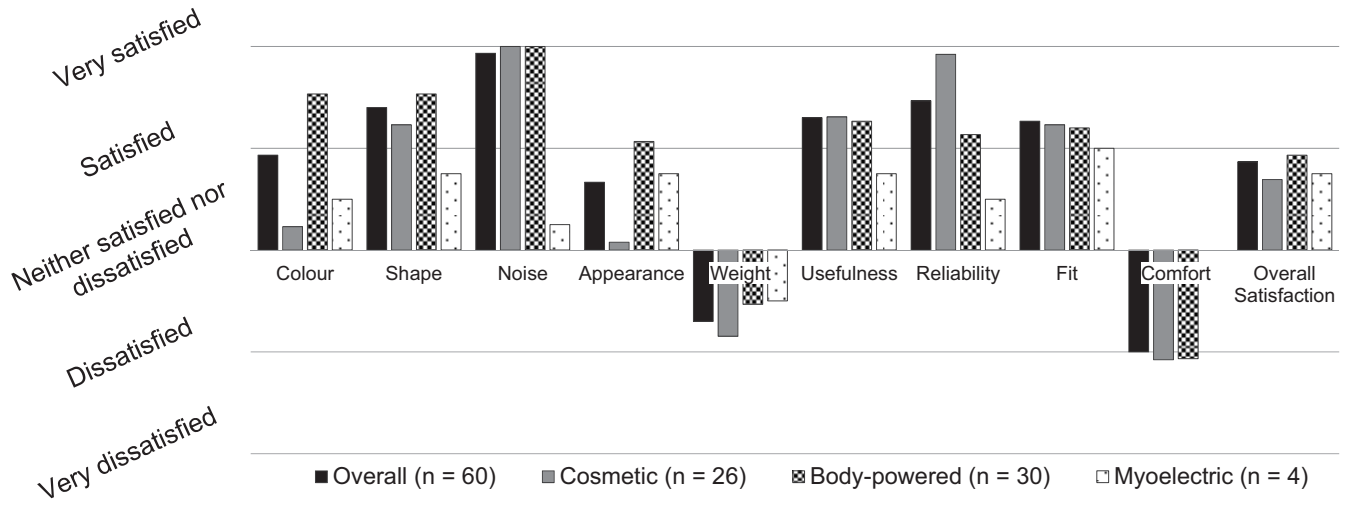

Fig. 2. Satisfaction levels across prostheses types.

\subsection{Reasons for non-wear/reduced wear patterns}

In an open-ended discussion common complaints were noted (Table 5). Patients were asked to rank suggested reasons for non-wear or reduced prosthesis use from the highest to lowest, showing that the main areas of concern were comfort, function, and maintenance (Fig. 3).

\subsection{Affordability/Appropriateness}

$22 \%(\mathrm{n}=13)$ of the patients surveyed had received government subsidy to enable them to obtain a prosthetic arm (Fig. 4). With this subsidy included, 33\% of the patients could afford a functional prosthesis in the price range INR 5,000-10,000 and $45 \%$ of these patients preferred an instalment mode of payment. $40 \%$ of all patients were able to afford a prosthesis in the range of INR $10,000-20,000$ and $83 \%$ of these patients preferred an instalment mode of payment.

$80 \%$ were able to afford up to INR 1,000 per year for repair and servicing. $10 \%$ of the patients voluntarily revealed that although they required prosthetic repair, spare parts or socket adjustment they had not visited the limb fitting centre due to time, distance, and finan- cial constraints. $95 \%$ owned or had an access to a mobile phone and $97 \%$ of these thought that they would benefit from an mHealth initiative for enhanced communication with the clinical team/service provider.

\section{Discussion}

\subsection{Sample population demographics}

$85 \%$ of the patients belonged to the age range of 15-54 years for whom the amputation affects livelihood earning capacity placing an economic burden on their family. The very high male to female ratio may be attributed to a higher exposure of men to occupational and traffic-accident trauma. The low qualification levels reflect general traits for this socialeconomic group [28]. As also expressed by few patients $(n=7)$, this would also mean that a prosthesis designed for such target patients should be sufficiently simple, easy to learn, easy to operate, and be intuitive. The mean SD duration from amputation to prosthesis fitting was 6 SD 4.9 years, however in the developed world studies [29-32] have highlighted that risk of prosthesis rejection is higher with a gap of more than 6 months 


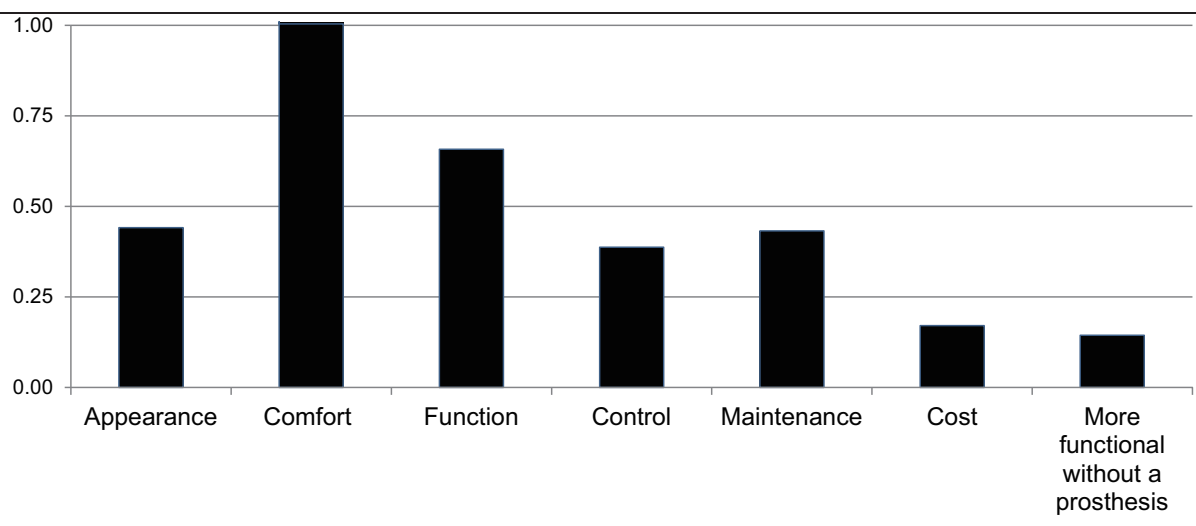

Fig. 3. Reasons for non-wear/reduced wear pattern.

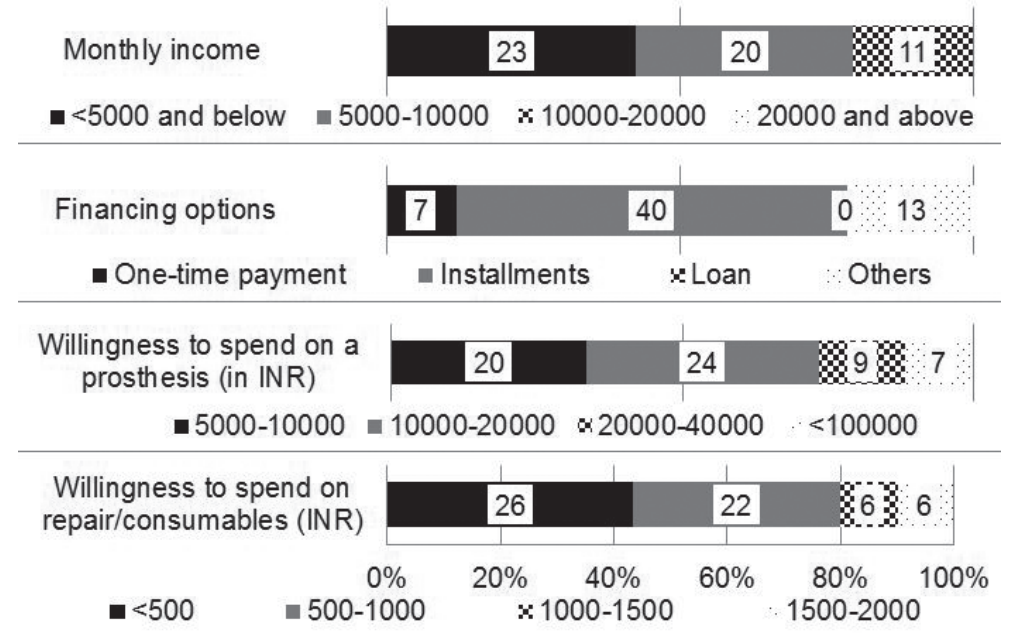

Fig. 4. Affordability aspects.

A majority of the patients $(65 \%)$ were from rural parts of India suggesting mechanization and unsafe practices in agriculture and other occupations. It is likely therefore, that actual incidence of limb loss in rural regions is far higher than reported [33]. This suggests an unmet need for mobile limb-fitting camps and prosthetic outreach activities in rural/semi-urban regions.

The telephone questionnaire format employed allowed patients with low literacy or impaired vision to be surveyed. However, this method excludes respondents with hearing impairment or language difficulties as well as those who do not have telephones who may be amongst the very poorest.

\subsection{Prosthesis history and usage}

The data presented here confirms that the UL prosthetic segment in India is dominated by body-powered arms and cosmetic arms. Even though these prostheses do not offer high functionality, our data support the claim that they are successful for being low cost, simple, rugged, and providing adequate cosmesis [34]. Cosmetic prostheses provide some functionality and are helpful in supporting or stabilizing an object [35]. Despite the lack of active grasping function, cosmetic prostheses raised the fewest user concerns, especially for socket discomfort, weight, perspiration. and strap irritation, again in agreement with previous studies [35,36].

In contrast with a Canadian study [37], all the patients in this study preferred a hand-shaped TD over a hook-shaped device despite the higher functional benefit it offers. Unsurprisingly, the lower share of myoelectric arms is likely due to high initial cost, and the costs and labour skills required for maintenance and repair. 


\subsection{Functional levels achieved through prosthesis}

Although many authors use the length of daily prosthesis use as an indication of success [29,30,38,39]. It has been suggested that a complex combination of functional usage, prosthetic wear, and function level achieved should be measured [8]. On both regaining previous levels of occupation [10] and functional level, currently available prostheses are not providing satisfactory results for the patients we surveyed.

\subsection{Design priorities for prosthesis}

Overall, the function of the prosthesis device was the highest priority followed by cost and durability as noted by a study comparing low-cost prosthetic feet in developing world setting [40]. However, the design parameters are usually inter-related and contradicting [41] and further detailed market research is required to define a prosthesis solution which is appropriately functional and durable.

\subsection{Satisfaction levels with current prosthesis}

Substantial gains in satisfaction might be achieved through lightweight design $(n=23)$ using newer material technologies [42]. Comfort might be enhanced by designing sockets to dissipate heat better $(n=14)$, or designing harnesses and sockets [43] to reduce skin irritation and perspiration $(n=11)$. Satisfaction with cosmesis could be increased with a wider range of skin colours for cosmetic gloves $(n=4)$.

\subsection{Reasons for non-wear/reduced wear patterns}

Rejection rates for cosmetic prostheses vary from $6 \%^{30}$ to $100 \%{ }^{36}$, while for body-powered prostheses rates are as high as $80 \%{ }^{37}$ and $87 \%$ [30]. Myoelectric prostheses have been the most extensively studied and rates vary from $0 \%$ [44] to $75 \%$ [45].

Harness/strap discomfort and weight emerged as particular concerns consistent with previous studies [9, $19,30,36,46,47]$. Reductions in weight and cost, and improvements in durability, functional grip, and wrist control and movement were also desired by bodypowered prosthesis users. Glove durability was also a concern. Users of myoelectric arms had increased maintenance requirements such as glove and battery replacement, in addition to the prosthetic higher cost and weight as also found previously $[48,49]$.
Minimising the time elapsed between initial preprosthetic assessments and the final fitting of a definitive prosthesis maximises long-term prosthetic use and enables a much greater rate of acceptance and functional integration of the artificial arm for the unilateral UL amputee $[29,50]$. This also allows patients to achieve an enhanced QoL earlier, potentially regain employment more easily, and may enable the service provider to treat more patients. In the present study $35 \%$ of the patients received their prosthesis in 4-6 weeks and around $65 \%$ waited for a longer duration. At least part of these delays might be addressed by prostheses that can be customized and fitted to patients in a shorter duration. Adjustments to amputation and artificial limb, as suggested by Sinha et al. [51,52], are key determinants of QoL, and carrying out a longitudinal study to investigate the impact of prosthetic rehabilitation could enhance our understanding and aid in improving prosthetic outcomes.

\subsection{Affordability/Appropriateness}

Cosmetic and body-powered prosthesis are available at a price lower than INR 7,000. However, patients were willing to invest a higher amount if the device offered enhanced functionality, durability and enabled them to perform activities of daily living. The preferred price-range for a functional prosthesis in this setting is less than INR 20,000 with an instalment mode of payment. The subsidy provided by the government to patients below the Poverty line [27] has a large effect in increasing access to prosthetic rehabilitation and is also important in enabling limb-fitting centres providing the prostheses to operate a sustainable business [53,54]. However, in case of a lack of institutional funding, utilising foreign-donated medical equipment and devices with user-specific innovations, as suggested by Barnett-Vanes et al. [55] can be an example of an alternative and viable approach that is helping to address this need.

\subsection{Study limitations}

It is important to note that the sample population was selected from a single limb-fitting centre, from one small region of the country. Predominantly, the patients were from low- and middle-income backgrounds and a considerable duration had elapsed between amputation and prosthesis fitting (6 SD 4.9 years). The number of patients using myoelectric arms was small $(n=4)$ and the whole sample size is small $(n=60)$, so is likely not to reflect the whole Indian population of patients needing prostheses (both upper limb and lower limb type), which increases by 17,000 annually [56] 


\section{Conclusions}

A questionnaire-based survey has been carried out on UL prostheses users from low- and middle-income backgrounds in Bangalore, India. The findings highlight the demand for low-cost prosthetic arms that can provide functional rehabilitation for patients. There is a requirement for more comfortable sockets and harness systems that are both cost-effective and durable. The major design priorities of the patients are functionality, comfort, and durability. Additionally, glove durability is a major area of concern. Further, minimising delays in limb provision and fitting could maximise long-term prosthetic use and enable a much greater rate of acceptance. Accurately capturing the patients' needs is the first step in translating new technology into appropriate solutions. Future work in this project will propose affordable prosthesis designs aiming to address these issues and hence enhance prosthetic rehabilitation in this developing world setting.

\section{Acknowledgements}

Mr. Soikat Ghosh Moulic, the staff and patients at Mobility India, Bangalore are gratefully thanked for the kind assistance with this work. Vikranth $\mathrm{H}$. Nagaraja's studentship is supported by the RCUK Digital Economy Programme grant number EP/G036861/1 (Oxford Centre for Doctoral Training in Healthcare Innovation). The work was also supported through a Wellcome Trust Affordable Healthcare in India award 103383/B/13/Z

\section{Conflict of interest}

The authors have no conflict of interest to report.

\section{References}

[1] Resnik L, et al. Advanced upper limb prosthetic devices: implications for upper limb prosthetic rehabilitation. Arch Phys Med Rehabil. 2012; 93(4): 710-717.

[2] Weir RF, Sensinger JW. Design of artificial arms and hands for prosthetic applications. In: Standard Handbook of Biomedical Engineering and Design, 2003.

[3] Cordella F, et al. Literature review on needs of upper limb prosthesis users. Front Neurosci. 2016; 10: Article 209.

[4] Biddiss EA, Chau TT. Upper limb prosthesis use and abandonment: A survey of the last 25 years. Prosthet Orthot Int. 2007: $31(3): 236-257$
[5] Biddiss EA, Chau TT. Upper-limb prosthetics: critical fac tors in device abandonment. Am J Phys Med Rehabil. 2007 86(12): 977-987.

[6] Biddiss EA, Chau TT. The roles of predisposing character istics, established need, and enabling resources on upper ex tremity prosthesis use and abandonment. Disabil Rehabil As sist Technol. 2007; 2(2): 71-84.

[7] Millstein S, Heger H, Hunter G. A review of the failures in use of the below elbow myoelectric prosthesis. Orthotics Prosthet. $1982 ; 36(2): 29-34$

[8] Gaine WJ, Smart C, Bransby-Zachary M. Upper limb trau matic amputees: Review of prosthetic use. J Hand Surg-Bri Eur. 1997; 22(1): 73-76.

[9] Atkins DJ, Heard DCY, Donovan WH. Epidemiologic overview of individuals with upper-limb loss and their re ported research priorities. J Prosthet Orthot. 1996; 8(1): 2-11.

[10] Biddiss EA, Beaton D, Chau TT. Consumer design priorities for upper limb prosthetics. Disabil Rehabil Assist Technol 2007; 2(6): 346-357.

[11] Brienna P, Zingalis G, Ritter S, Mehta K. A review of cur rent upper-limb prostheses for resource constrained settings. 2015 IEEE In Global Humanitarian Technology Conference (GHTC), IEEE, 2015: 52-58.

[12] Andrysek J. Lower-limb prosthetic technologies in the devel oping world: a review of literature from 1994-2010. Prosthe Orthot Int. 2010; 34(4): 378-398.

[13] Harkins CS, McGarry A, Buis A. Provision of prosthetic and orthotic services in low-income countries: A review of the literature. Prosthet Orthot Int. 2013; 37(5): 353-361.

[14] Wyss D, Lindsay S, Cleghorn WL, Andrysek J. Priorities in lower limb prosthetic service delivery based on an interna tional survey of prosthetists in low-and high-income coun tries. Prosthet Orthot Int. 2015; 39 (2): 102-11.

[15] Ikeda AJ, Grabowski, AM, Lindsley A, Sadeghi-Demneh E Reisinger KD. A scoping literature review of the provision of orthoses and prostheses in resource-limited environments 2000-2010. Part one: considerations for success. Prosthet Or thot Int. 2014; 38(4): 269-86.

[16] Ikeda AJ, Grabowski, AM, Lindsley A, Sadeghi-Demneh E Reisinger KD. A scoping literature review of the provision of orthoses and prostheses in resource-limited environments 2000-2010. Part two: research and outcomes. Prosthet Orthot Int. 2014; 38(5): 343-62.

[17] Magnusson L, Ahlström G, Ramstrand N, Fransson EI Malawian prosthetic and orthotic users' mobility and satisfaction with their lower limb assistive device. J Rehabil Med 2013; 45(4): 385-391.

[18] Magnusson L, Ramstrand N, Fransson EI, Ahlström G. Mo bility and satisfaction with lower-limb prostheses and orthoses among users in Sierra Leone: A cross-sectional study. J Rehabil Med. 2014; 46(5): 438-446.

[19] Kumar B, Bhat AK, Acharya KN. Prosthetic rehabilitation in traumatic upper limb amputees (an Indian perspective). Arch Orthop Trauma Surg. 2003; 123(7): 363-366.

[20] Narang JC, Mathur BP, Singh P, Jape VS. Clinical survey o upper extremity amputees in India. Orthotics Prosthet. 1986; 40(2): 29-37.

[21] Sharma VP, Agarwal AK, Mishra VS, Singhal AK. A clinical study of upper limb amputees. Indian J Phys Med Rehabil. 1990; 3(1): 33-36

[22] Mathi E, Savla D, Sreeraj SR, Mishra S. Quality of Life in Transtibial Amputees: An Exploratory Study Using TAPES-R Questionnaire. Int J Health Sci Res. 2014; 4(7): 162-168

[23] Sharma RK, Singh B, Sharma S. Efficacy of Cognitive Be- 
haviour Therapy and Quality Of Life in the Amputees. Int $J$ Indian Psychol. 2016; 3(7): 151-166.

[24] Gallagher P, MacLachlan M. Development and psychometric evaluation of the Trinity Amputation and Prosthesis Experience Scales (TAPES). Rehabil Psychol. 2000; 45(2): 130.

[25] Hill W, Stavdahl Ø, Hermansson LN, Kyberd P, Swanson S, Hubbard S. Functional outcomes in the WHO-ICF model: establishment of the Upper Limb Prosthetic Outcome Measures Group. J Prosthet Orthot. 2009; 21(2): 115-9.

[26] World Health Organization. Towards a Common Language for Functionary, Disability and Health: ICF Beginner's Guide (WHO/EIP/GPE/CAS/01.3). Geneva: WHO; 2002.

[27] Press Notes on Poverty Estimates - 2011-12. Government of India Planning Commission, http://planningcommission. nic.in/news/pre_pov2307.pdf (2012, accessed on: 18 Oct 2016).

[28] Literacy and Level of Education. http://censusindia.gov.in/ Census_And_You/literacy_and_level_of_education.aspx, (2011, accessed on: 18 Oct 2016).

29] Malone J, Flemming L, Roberson J, et al. Immediate, early and late postsurgical management of upper-limb amputation. J Rehabil Res Dev. 1984; 21: 33-41.

30] Kejlaa GH, et al. Consumer concerns and the functional value of prostheses to upper limb amputees. Prosthet Orthot Int. 1993; 17: 157-163.

[31] Strait E. Prosthetics in developing countries. Prosthetic Resident 2006.

[32] Lake C. Upper-limb prosthetics: Using evidence-based practice to enhance patient care experiences. Acad Today. 2011 A4-A7.

33] Stevens P. Prosthetics in Resource-Limited Countries. The $O \& P$ EDGE. 2015.

[34] O'Keeffe B. Prosthetic rehabilitation of the upper limb amputee. Indian J Plast Surg. 2011; 44(2): 246.

[35] Fraser CM. An evaluation of the use made of cosmetic and functional prostheses by unilateral upper limb amputees. Prosthet Orthot Int. 1998; 22: 216-223.

36] van Lunteren A, van Lunteren-Gerritsen GHM, Stassen HG, Zuithoff MJ. A field evaluation of arm prostheses for unilateral amputees. Prosthet Orthot Int. 1983; 7: 141.

[37] Millstein S, Heger H, Hunter G. Prosthetic use in adult upper limb amputees: A comparison of the body-powered and electrically powered prostheses. Prosthet Orthot Int. 1986; 10: 27 34.

38] Burkhalter W, Carmona LS. The upper-extremity amputee. Early and immediate post-surgical prosthetic fitting. $J$ Bone Joint Surg Am. 1976; 58A: 46-51.

39] Roeschlein RA, Domholdt E. Factors related to successful upper extremity prosthetic use. Prosthet Orthot Int. 1989; 13: 14-18.

[40] Adalarasu K, Mohan J, Mathur MK. Comparison on Jaipur, SACH and Madras foot. Int J Adv Eng Sci Technol. 2011; 6 : 187-92.
[41] Craig J. Prosthetic feet for low-income countries. J Prosthe Orthot. 2005; 17(4): S47-S49.

[42] Sitek AJ. et al. Development of an inexpensive upperextremity prosthesis for use in developing countries. J Pros thet Orthot. 2004; 16(3): 94-102.

[43] Thomas HD, Bhambhvani H, Zagorulya M, Pankin AM. Af fordable, modular, and breathable upper-limb prosthetic sock ets for use in underdeveloped areas with hot, humid climates. J Young Investig. 2015; 28(4): 45-54.

[44] Dalsey R, Gomez W, Seitz WH, et al. Myoelectric pros thetic replacement in the upper-extremity amputee. Orthop Rev. 1989; 18: 697-702

[45] Crandall RC, Tomhave W. Pediatric unilateral below-elbow amputees: Retrospective analysis of 34 patients given multiple prosthetic options. J Pediatr Orthop. 2002.; 22: 380-383.

[46] Dudkiewicz I, Gabrielov R, Seiv-Ner I, et al. Evaluation of prosthetic usage in upper limb amputees. Disabil Rehabil. 2004; 26: 60-63.

[47] Fernandez-Palazzi F, de Gutierrez DP, Paladino R. The care of the limb deficient child in Venezuela. Prosthet Orthot Int 1991; 15: 156-159.

[48] Balance R, Wilson BN, Harder JA. Factors affecting myoelec tric prosthetic use and wearing patterns in the juvenile unilateral below-elbow amputee. Can J Occup Ther. 1989; 56 132-137.

[49] Datta D, Kingston J, Ronald J. Myoelectric prostheses for below-elbow amputees: The Trent experience. Int Disabi Stud. 1989; 11: 167-170.

[50] Esquenazi A. Pain management post amputation. In: TN Monga M Grabois (eds) Pain Management in Rehabilitation. New York, NY: Demos Medical Publishing, 2002, pp. 191 202.

[51] Sinha R, van den Heuvel WJ, Arokiasamy P, van Dijk JP. Influence of adjustments to amputation and artificial limb on quality of life in patients following lower limb amputation. Int J Rehab Res. 2014; 37(1): 74-79.

[52] Sinha R, van den Heuvel WJ, Arokiasamy P. Factors affecting quality of life in lower limb amputees. Prosthet Orthot Int 2011; 35(1): 90-96.

[53] Ghosh-Moulic S. Personal communication, 29 July 2013.

[54] Marino M. et al. Access to prosthetic devices in developing countries: Pathways and challenges. 2015 IEEE In Global Humanitarian Technology Conference (GHTC), IEEE, 2015: 45 51.

[55] Barnett-Vanes A, Maruthappu M, Shalhoub J, Homer Vanniasinkam S, Panagamuwa B. Redistributing prostheses from Britain to Sri Lanka. The Bulletin of the Royal College of Surgeons of England. 2015; 97(2): 82-86.

[56] Meanley S. Different approaches and cultural consideration in Third World prosthetics Prosthet Orthot Int. 1995; 19: 176 180. 